Article

\title{
Prognostic Impact of Serum Free Light Chain Ratio Normalization in Patients with Multiple Myeloma Treated within the GMMG-MM5 Trial
}

\author{
Eva-Maria Klein ${ }^{1,2}, *$, Diana Tichy ${ }^{3}$, Hans J. Salwender ${ }^{4}$, Elias K. Mai ${ }^{1}{ }^{\circledR}$, Jan Duerig ${ }^{5}$, Katja C. Weisel ${ }^{6}$, \\ Axel Benner ${ }^{3}$, Uta Bertsch ${ }^{1,7}$, Mabast Akhavanpoor ${ }^{1}$, Britta Besemer ${ }^{8}$, Markus Munder ${ }^{9}$, \\ Hans-Walter Lindemann ${ }^{10}$, Dirk Hose ${ }^{1}$, Anja Seckinger ${ }^{1} \oplus$, Steffen Luntz ${ }^{11}$, Anna Jauch ${ }^{12}$, Ahmet Elmaagacli ${ }^{13}$, \\ Stephan Fuhrmann ${ }^{14}{ }^{(}$, Peter Brossart ${ }^{15}$, Martin Goerner ${ }^{16}$, Helga Bernhard ${ }^{17}$, Marc S. Raab ${ }^{1}$, Igor W. Blau ${ }^{18}$, \\ Mathias Haenel ${ }^{19}$, Christof Scheid ${ }^{20}$, Hartmut Goldschmidt ${ }^{1,7}$ and on behalf of the German-Speaking Myeloma \\ Multicenter Group (GMMG) ${ }^{\dagger}$
}

check for updates

Citation: Klein, E.-M.; Tichy, D.; Salwender, H.J.; Mai, E.K.; Duerig, J.; Weisel, K.C.; Benner, A.; Bertsch, U.; Akhavanpoor, M.; Besemer, B.; et al. Prognostic Impact of Serum Free Light Chain Ratio Normalization in Patients with Multiple Myeloma Treated within the GMMG-MM5 Trial. Cancers 2021, 13, 4856. https:/ / doi.org/10.3390/cancers13194856

Academic Editor: Antonino Neri

Received: 31 August 2021

Accepted: 22 September 2021

Published: 28 September 2021

Publisher's Note: MDPI stays neutral with regard to jurisdictional claims in published maps and institutional affiliations.

Copyright: (c) 2021 by the authors. Licensee MDPI, Basel, Switzerland. This article is an open access article distributed under the terms and conditions of the Creative Commons Attribution (CC BY) license (https:// creativecommons.org/licenses/by/ $4.0 /)$.
1 Department of Medicine V, Hematology, Oncology and Rheumatology, University of Heidelberg, 69120 Heidelberg, Germany; elias.mai@med.uni-heidelberg.de (E.K.M.); uta.bertsch@med.uni-heidelberg.de (U.B.); m-moohialdin@gmx.de (M.A.); dirk_hose@yahoo.de (D.H.); anja.seckinger@gmx.de (A.S.); marc.raab@med.uni-heidelberg.de (M.S.R.); hartmut.goldschmidt@med.uni-heidelberg.de (H.G.)

2 Department of Internal Medicine 5, Klinikum Nuremberg, Paracelsus Medical University, 90419 Nuremberg, Germany

3 Division of Biostatistics, German Cancer Research Center (DKFZ), 69120 Heidelberg, Germany; d.tichy@dkfz-heidelberg.de (D.T.); benner@dkfz-heidelberg.de (A.B.)

4 Asklepios Tumorzentrum Hamburg, AK Altona and AK St. Georg, 22763 Hamburg, Germany; h.salwender@asklepios.com

5 Department of Hematology, University Clinic Essen, 45147 Essen, Germany; jan.duerig@uk-essen.de

6 Department of Oncology, Hematology and Bone Marrow Transplantation with Section of Pneumology, University Medical Center Hamburg-Eppendorf, 20246 Hamburg, Germany; k.weisel@uke.de

National Center for Tumor Diseases, 69120 Heidelberg, Germany

8 Department of Hematology, Oncology and Immunology, University Hospital Tübingen, 72076 Tübingen, Germany; britta.besemer@med.uni-tuebingen.de

9 Department of Internal Medicine III, University Medical Center Mainz, 55131 Mainz, Germany; munder@uni-mainz.de

10 Department of Hematology and Oncology, Katholisches Krankenhaus Hagen, 58097 Hagen, Germany; w.lindemann@kkh-hagen.de

11 Coordination Centre for Clinical Trials (KKS) Heidelberg, 69120 Heidelberg, Germany; steffen.luntz@med.uni-heidelberg.de

12 Institute of Human Genetics, University of Heidelberg, 69120 Heidelberg, Germany; anna.jauch@med.uni-heidelberg.de

13 Department of Hematology and Oncology, Asklepios Hospital Hamburg St. Georg, 20099 Hamburg, Germany; a.elmaagacli@asklepios.com

14 Department of Hematology and Oncology, Helios Hospital Berlin Buch, 13125 Berlin, Germany; stephan.fuhrmann@helios-gesundheit.de

15 Department of Internal Medicine, Oncology, Hematology, Immuno-Oncology and Rheumatology/Clinical Immunology, University Hospital Bonn, 53127 Bonn, Germany; peter.brossart@ukb.uni-bonn.de

16 Department of Hematology, Oncology and Palliative Care, Klinikum Bielefeld, 33604 Bielefeld, Germany; martin.goerner@klinikumbielefeld.de

17 Internal Medicine V, Klinikum Darmstadt, 64283 Darmstadt, Germany; helga.bernhard@mail.klinikum-darmstadt.de

18 Medical Clinic, Charité University Medicine Berlin, 13353 Berlin, Germany; igor.blau@charite.de

19 Department of Internal Medicine III, Klinikum Chemnitz, 09116 Chemnitz, Germany; m.haenel@skc.de

20 Department of Internal Medicine I, University Hospital Cologne, 50937 Cologne, Germany; c.scheid@uni-koeln.de

* Correspondence: eva-maria.klein@etklein.de; Tel.: +49-911-398-114957

$\dagger$ Membership of the German-Speaking Myeloma Multicenter Group (GMMG) is provided in the Acknowledgments.

Simple Summary: For multiple myeloma (MM) patients with measurable disease, there is no recommendation to monitor serum free light chains during therapy. However, this could provide 
important information in terms of prognosis. We investigated the prognostic impact of serum free light chain ratio (FLCr) normalization in 590 patients with secretory MM during first-line treatment within the German-Speaking Myeloma Multicenter Group MM5 trial. We are able to show that there is an increasing percentage of patients who achieve FLCr normalization during therapy. Importantly, we demonstrate that FLCr normalization at any time before the start of maintenance is significantly associated with prolonged progression-free and overall survival in multivariable time-dependent Cox regression analyses. This suggests that FLCr normalization during therapy is an important and simple way to assess prognostic factor in MM and supports the serial measurement of serum free light chains during therapy, even in patients with secretory MM.

Abstract: We investigated the prognostic impact of time-dependent serum free light chain ratio (FLCr) normalization in 590 patients with secretory multiple myeloma (MM) during first-line treatment within the German-Speaking Myeloma Multicenter Group MM5 trial. Serum free light chains (sFLC) were assessed by the Freelite test at baseline, after induction, mobilization, autologous blood stem cell transplantation, consolidation and every three months during maintenance or follow up within two years after the start of maintenance. The proportion of patients with a normal or normalized FLCr increased from $3.6 \%$ at baseline to $23.2 \%$ after induction and $64.7 \%$ after consolidation. The achievement of FLCr normalization at any one time before the start of maintenance was associated with significantly prolonged progression-free survival (PFS) $(p<0.01$, hazard ratio (HR) $=0.61,95 \%$ confidence interval $(95 \% \mathrm{CI})=0.47-0.79)$ and overall survival $(\mathrm{OS})(p=0.02, \mathrm{HR}=0.67,95 \% \mathrm{CI}=0.48-0.93)$ in multivariable time-dependent Cox regression analyses. Furthermore, reaching immune reconstitution, defined as the normalization of uninvolved immunoglobulins, before maintenance was associated with superior PFS ( $p=0.04, \mathrm{HR}=0.77,95 \% \mathrm{CI}=0.60-0.99)$ and OS ( $p=0.01, \mathrm{HR}=0.59$, $95 \% \mathrm{CI}=0.41-0.86$ ). We conclude that FLCr normalization during therapy is an important favorable prognostic factor in MM. Therefore, we recommend serial measurements of sFLC during therapy until achieving FLCr normalization, even in patients with secretory MM.

Keywords: multiple myeloma; prognostic factors; serum free light chain ratio normalization; immune reconstitution; time-dependent analysis

\section{Introduction}

Multiple myeloma (MM) is a cancer of the bone marrow, characterized by a clonal proliferation of plasma cells producing monoclonal protein. The monoclonal protein can be either a complete immunoglobulin consisting of two heavy and two light chains or, in the case of light chain MM, light chains only. However, in patients with $\lg$, $\lg \mathrm{A}, \lg \mathrm{M}, \lg \mathrm{D}$ or $\lg \mathrm{E}$ MM, more light chains are also produced than heavy chains, leading to a measurable increase in light chains in the serum and also in the urine after the renal reabsorption capacity is exceeded [1].

An abnormal serum free light chain ratio (kappa/lambda, FLCr) can be found in approximately $95-98 \%$ of patients with newly diagnosed MM $[2,3]$. The prognostic impact of the FLCr at diagnosis was demonstrated in several clinical trials [2-5]. Therefore, according to the recommendations of the International Myeloma Working Group (IMWG), serum free light chains (sFLC) should be assessed at baseline in MM [6]. Further indications for measuring sFLC in MM are the screening for MM, the monitoring of a part of the patients with previously called asecretory MM (involved sFLC $\geq 100 \mathrm{mg} / \mathrm{L}$ provided an abnormal FLCr) and the determination of the stringent complete response (sCR) [6-8]. For MM patients with measurable disease by a serum monoclonal protein $\geq 10 \mathrm{~g} / \mathrm{L}$ or a light chain excretion in the $24 \mathrm{~h}$ urine $\geq 200 \mathrm{mg}$ per day, there is no recommendation for monitoring of sFLC during therapy yet [9].

Nonetheless, sequential measuring sFLC in these patients might be beneficial. LopezAnglada and colleagues were able to demonstrate in an analysis on patients treated in three 
phase-three trials of the PETHEMA/GEM that achieving a normalization of the FLCr after treatment is associated with prolonged progression-free survival (PFS) and overall survival (OS) and that the persistence of an involved sFLC $\geq 100 \mathrm{mg} / \mathrm{L}$ after the end of treatment has a negative prognostic impact [10]. Another analysis showed that in MM patients achieving no complete response (CR) during first-line therapy, an FLCr normalization at the time point of best response also has an independent beneficial effect on PFS and OS [11]. Furthermore, Dejoie and colleagues recently published a proposal for a modification of the IMWG response criteria, replacing $24 \mathrm{~h}$ urine measurements with sFLC in the response assessment of patients with secretory MM [12].

Besides an abnormal FLCr, immunoparesis is a hallmark of MM since the expansion of clonal plasma cells leads to a displacement of normal plasma cells and therefore decreased production of polyclonal immunoglobulins. Accordingly, immunoparesis accounts for an adverse prognosis in newly diagnosed, as well as relapsed, MM [13-15]. In turn, achieving a reconstitution of polyclonal immunoglobulins during the course of therapy is associated with prolonged PFS and OS. The recovery of polyclonal immunoglobulins one year after autologous blood stem cell transplantation (ASCT) is associated with a favorable prognosis [16].

The aim of our study is to investigate FLCr normalization during the course of therapy within the German-Speaking Myeloma Multicenter Group (GMMG) MM5 trial [17] and its impact on PFS and OS. In addition, we evaluate the importance of achieving immune reconstitution during therapy.

\section{Materials and Methods}

\subsection{MM5 Trial}

Newly diagnosed transplant-eligible MM patients with measurable disease were included in the prospective multicenter phase-three trial MM5 (EudraCT No. 2010-019173-16) and randomized to one of four different treatment arms. Eligibility criteria, design and primary endpoints of the trial have been published $[17,18]$. After randomization, patients received induction therapy with three cycles of bortezomib, doxorubicin and dexamethasone (PAd, arms A1 and B1) or bortezomib, cyclophosphamide and dexamethasone (VCD, arms A2 and B2). Then stem cell mobilization and subsequent melphalan high-dose therapy and ASCT were performed according to local protocols. Afterwards, lenalidomide consolidation and maintenance were conducted. Patients received lenalidomide maintenance for two years in arms A1 and A2 or until the achievement of CR in arms B1 and B2 (Figure S1; Material S1). The MM5 trial was approved by the local ethics committees of all participating centers (leading ethics committee University of Heidelberg AFmu-119/2010). All patients gave written informed consent.

\subsection{Assessment of sFLC and Immunoglobulins}

The Freelite test (The Binding Site Group Ltd., Birmingham, Great Britain) was used to prospectively quantify sFLC centrally at inclusion, after induction, stem cell mobilization, ASCT, consolidation and every three months during maintenance or follow up within two years after the start of maintenance [19]. The immunoglobulins IgG, IgA and IgM were prospectively assessed at the same time points. For the definition of FLCr normalization, the established reference range by Katzmann et al. for the kappa/lambda ratio of 0.26-1.65 was used [20]. In the case of renal insufficiency (creatinine $>2 \mathrm{mg} / \mathrm{dL}$ and/or glomerular filtration rate $<40 \mathrm{~mL} / \mathrm{min}$ ), the adapted range $0.37-3.1$ for FLCr was applied [21]. Immunoparesis was defined by the suppression of at least one uninvolved immunoglobulin [22] For the achievement of immune reconstitution, the normalization of all uninvolved immunoglobulins was required. The following reference ranges were used: $\operatorname{IgG} 7.0-16.0 \mathrm{~g} / \mathrm{L}$, IgA $0.7-4.0 \mathrm{~g} / \mathrm{L}$ and $\operatorname{IgM} 0.4-2.3 \mathrm{~g} / \mathrm{L}$. 


\subsection{Statistical Methods}

The achievement of FLCr normalization was determined for patients on study at baseline, after induction, stem cell mobilization, ASCT, consolidation and every three months during maintenance or follow up until the end of the study. Thus, the values of FLCr normalization are yes, no and missing. In the second step, we consolidated the received information and determined if FLCr normalization was achieved at any time until the start of maintenance at the latest, irrespective of whether the achievement was lost in between. Thereby, the date of first achievement was used to model the time from randomization to the first achievement of FLCr normalization. The achievement of immune reconstitution was analogously determined. In addition, the achievement of $C R$ after consolidation was assessed.

A multivariable Cox regression model with time-dependent covariates was applied to analyze the impact of FLCr normalization and immune reconstitution until the start of maintenance at the latest on PFS and OS. FLCr normalization, immune reconstitution and $\mathrm{CR}$ after consolidation were modeled as time-dependent covariates. The set of fixed covariates consisted of age, the International Staging System (ISS), cytogenetic risk and treatment arm. The Simon-Makuch estimators were derived to present the estimated risk of progression or death under the state of achieved FLCr normalization or immune reconstitution [23]. The Simon-Makuch plots show the impact of time-dependent variables on PFS and OS, taking the time-dependent change of the variables into account. Here, the survival times until a potential achievement of FLCr normalization/immune reconstitution and after a potential achievement are separately shown in two curves. Therefore, it is possible that one patient can be found in two curves. Patients who never achieve FLCr normalization are shown in the curve "before FLCr normalization" as well as patients who start with an abnormal FLCr and achieve a normalization during therapy. Then the patients who achieve a normalization can be found in the curve "after FLCr normalization" as well as patients who already started with a normal FLCr.

Furthermore, the prognostic impact of FLCr normalization at end of induction and consolidation, respectively, and immune reconstitution after consolidation were assessed by an equivalent multivariable Cox regression model.

To evaluate a previously described prognostic effect of FLCr at diagnosis, the impact of an FLCr of 1/32-32 vs. $<1 / 32$ or $>32$ at baseline on PFS and OS was examined in a univariate Cox regression analysis, according to Snozek et al. [2]. The curves for PFS and OS and the corresponding 95\% confidence interval (CI) were derived using the Kaplan-Meier method [24].

Values of $p<0.05$ were considered statistically significant. The analyses were conducted using R version 3.6.2 (https:/ / www.R-project.org, accessed on 17 September 2021).

\section{Results}

\subsection{Patient Cohort}

The expanded population of the MM5 trial consisted of 604 patients [25]. Three of them were excluded due to a violation of the inclusion criteria. Among 601 patients of the ITT population, a number of 590 patients were evaluable for multivariable time-toevent analysis and made up the corresponding analysis population. For 11 patients, FLCr normalization or immune reconstitution could not be determined due to missing values of sFLC, immunoglobulins, creatinine, glomerular filtration rate or missing an assessment date of sFLC or immunoglobulins.

The baseline characteristics of the analysis population $(n=590)$ can be found in Table 1 . After the end of consolidation, 126 of 456 patients on study at the start of the second cycle of consolidation achieved a CR and 320 a non-CR. Ten patients on study had no response assessment after consolidation.

An FLCr between $1 / 32$ and 32 vs. $<1 / 32$ or $>32$ at baseline was associated with prolonged PFS $(p=0.01$, hazard ratio $(\mathrm{HR})=0.74,95 \% \mathrm{CI}=0.59-0.94)$ and $\mathrm{OS}(p=0.01$, $\mathrm{HR}=0.62,95 \% \mathrm{CI}=0.44-0.88$ ) in univariate Cox regression analyses (Figure 1 ). 
Table 1. Baseline characteristics of the analysis population.

\begin{tabular}{|c|c|c|}
\hline Variable & $n(n=590)$ & $\%$ \\
\hline $\operatorname{Sex}(n=590)$ & & \\
\hline Female & 242 & 41.0 \\
\hline Male & 348 & 59.0 \\
\hline Age $(n=590)$ & & \\
\hline Median (range) & \multicolumn{2}{|c|}{$59(32-70)$ years } \\
\hline \multicolumn{3}{|c|}{ Myeloma subtype $(n=590)$} \\
\hline $\operatorname{IgG}$ & 364 & 61.7 \\
\hline $\operatorname{Ig} \mathrm{A}$ & 121 & 20.5 \\
\hline Bence-Jones & 105 & 17.8 \\
\hline \multicolumn{3}{|c|}{ Light chain isotype $(n=590)$} \\
\hline Kappa & 402 & 68.1 \\
\hline Lambda & 188 & 31.9 \\
\hline \multicolumn{3}{|l|}{ Calcium $(n=590)$} \\
\hline$>2.65 \mathrm{mmol} / \mathrm{L}$ & 79 & 13.4 \\
\hline$\leq 2.65 \mathrm{mmol} / \mathrm{L}$ & 511 & 86.6 \\
\hline \multicolumn{3}{|c|}{ Renal insufficiency * $(n=590)$} \\
\hline Yes & 66 & 11.2 \\
\hline No & 524 & 88.8 \\
\hline \multicolumn{3}{|c|}{ Hemoglobin $(n=590)$} \\
\hline$<10 \mathrm{~g} / \mathrm{dL}$ & 304 & 51.5 \\
\hline$\geq 10 \mathrm{~g} / \mathrm{dL}$ & 286 & 48.5 \\
\hline \multicolumn{3}{|c|}{ Bone disease $^{* *}(n=590)$} \\
\hline Yes & 534 & 90.5 \\
\hline No & 56 & 9.5 \\
\hline \multicolumn{3}{|l|}{ ISS $(n=590)$} \\
\hline I & 226 & 38.3 \\
\hline II & 204 & 34.6 \\
\hline III & 160 & 27.1 \\
\hline \multicolumn{3}{|c|}{ Adverse cytogenetics ${ }^{* * *}(n=527)$} \\
\hline Yes & 267 & 50.7 \\
\hline No & 260 & 49.3 \\
\hline \multicolumn{3}{|l|}{ LDH $(n=588)$} \\
\hline$<308 \mathrm{U} / \mathrm{L}$ & 551 & 93.7 \\
\hline$\geq 308 \mathrm{U} / \mathrm{L}$ & 37 & 6.3 \\
\hline \multicolumn{3}{|c|}{ Abnormal FLCr $(n=584)$} \\
\hline Yes & 563 & 96.4 \\
\hline No & 21 & 3.6 \\
\hline \multicolumn{3}{|c|}{ Immunoparesis $(n=588)$} \\
\hline Yes & 535 & 91.0 \\
\hline No & 53 & 9.0 \\
\hline
\end{tabular}

Abbreviations: ISS, International Staging System; LDH, lactat dehydrogenase; FLCr, free light chain ratio. * Creatinine $>2 \mathrm{mg} / \mathrm{dL}$ and/or glomerular filtration rate $<40 \mathrm{~mL} / \mathrm{min}$. ** One or more osteolytic lesions. *** Deletion $17 \mathrm{p} 13$, translocation $\mathrm{t}(4 ; 14)$ or gain $1 \mathrm{q} 21$ more than three copies. 

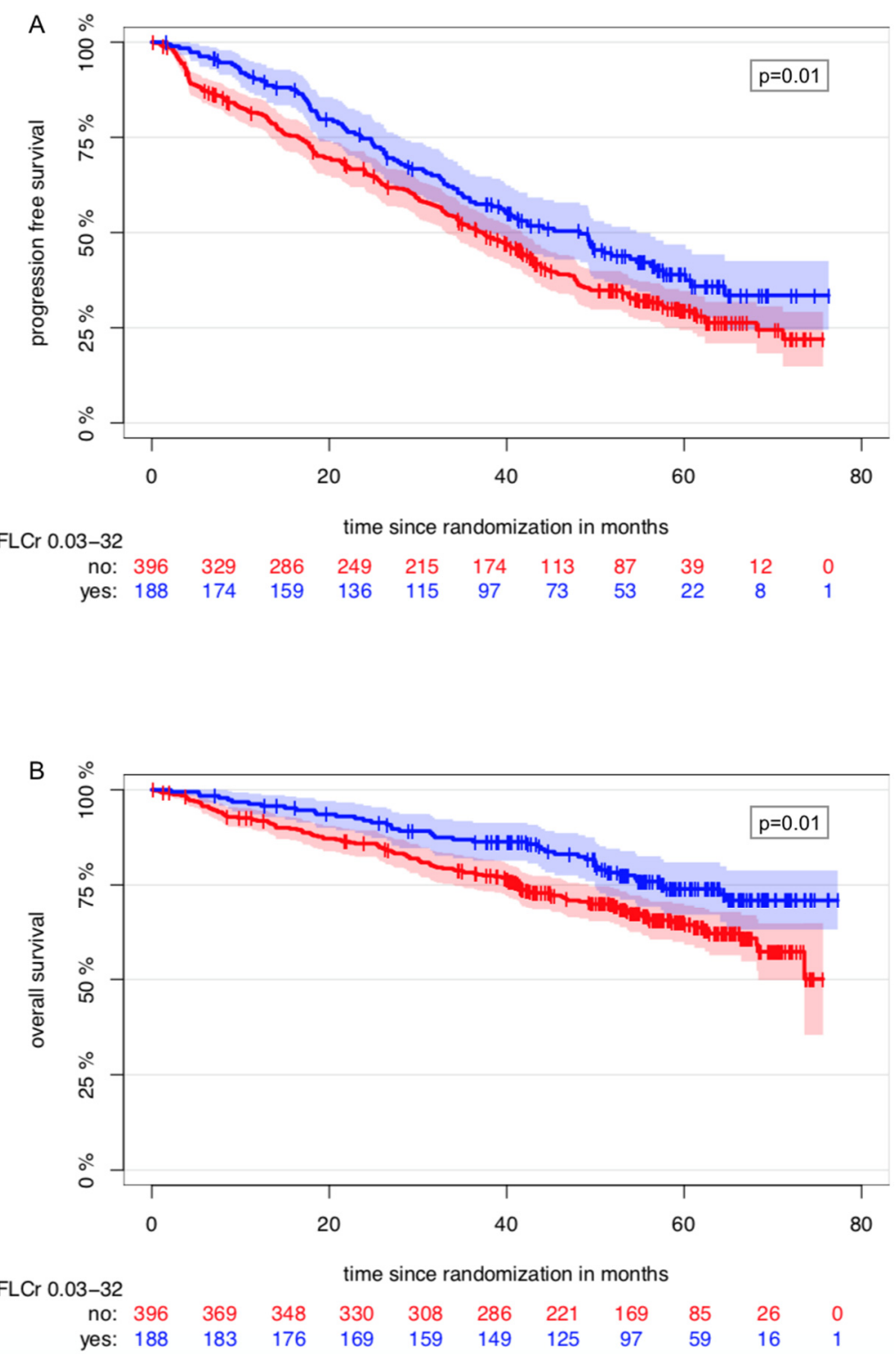

Figure 1. Kaplan-Meier Estimator of the impact of the FLCr at baseline on PFS (A) and OS (B).

\subsection{FLCr Normalization during Therapy in the MM5 Trial and Its Impact on PFS and OS}

The percentage of patients with a normal FLCr increased from 3.6\% (21/590) at baseline to $23.2 \%(131 / 564)$ after induction, $48.5 \%(249 / 513)$ after ASCT and 64.7\% (295/456) after consolidation therapy (Figure 2). During maintenance therapy, the percentage slowly decreased from $61.7 \%(263 / 426)$ after three months to $55.4 \%$ (209/377) after 12 months to $48.1 \%(140 / 291)$ after 24 months.

Among 590 evaluable patients for multivariable regression analyses, 401 patients achieved a FLCr normalization at any time point before the start of maintenance. A normalization of the FLCr until the start of maintenance at the latest significantly prolonged PFS $(p<0.01, \mathrm{HR}=0.61,95 \% \mathrm{CI}=0.47-0.79)$ and $\mathrm{OS}(p=0.02, \mathrm{HR}=0.67,95 \% \mathrm{CI}=0.48-0.93)$ in the multivariable time-dependent Cox regression analyses (Table 2). This impact was not associated with a deep response (CR vs. non-CR) after consolidation. Furthermore, ISS II and III compared to ISS I and the presence of high-risk cytogenetics were significantly associated with an inferior PFS and OS. Lenalidomide maintenance until the achievement of CR (study arms B1 and B2) compared to a fixed duration of two years (study arms A1 and A2) was linked to a shorter OS (Table 2). Figure 3A,B present the Simon-Makuch estimators on the risk of progression and death depending on the achievement of FLCr normalization. 


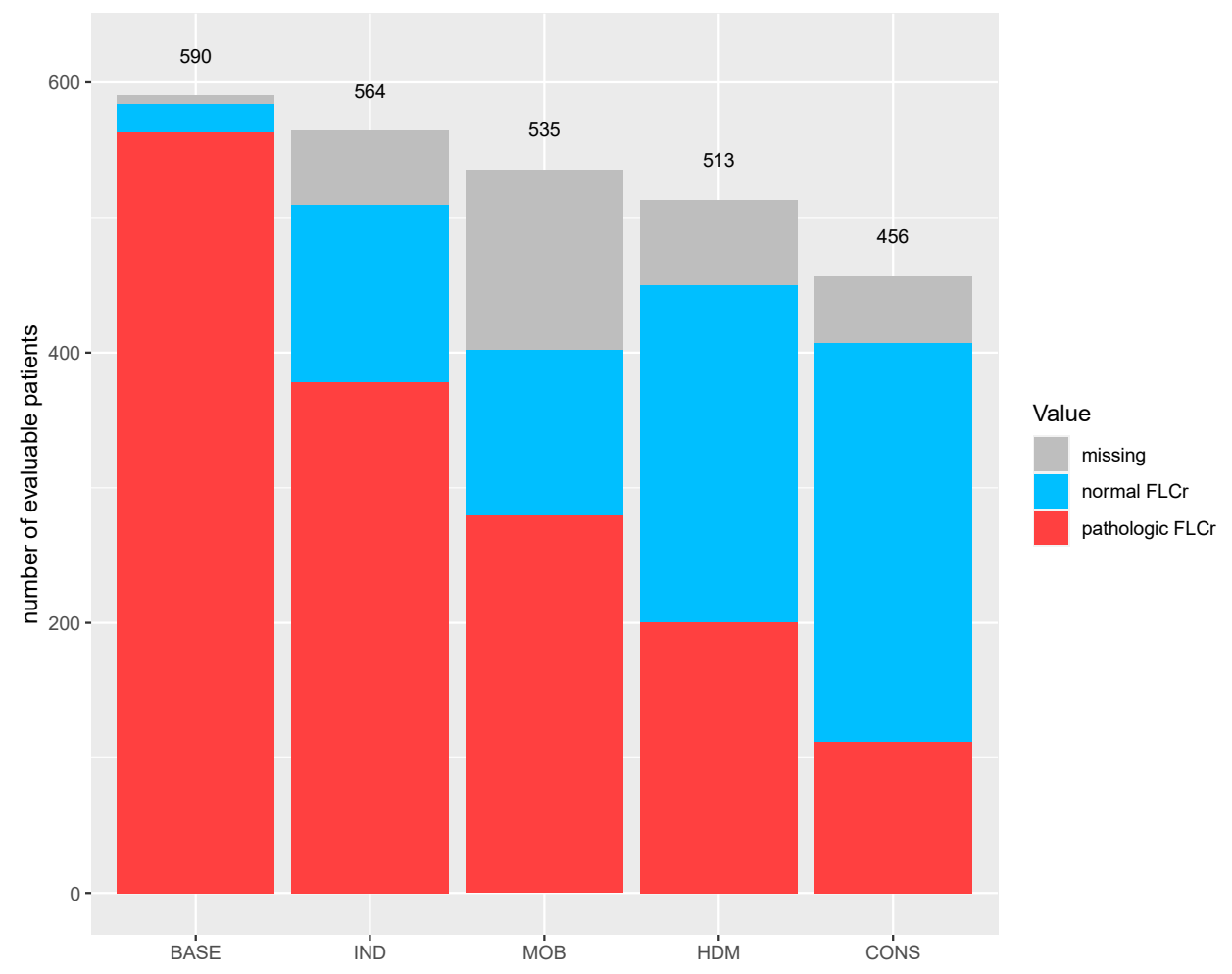

Figure 2. FLCr normalization during first-line therapy in the MM5 trial. The number of evaluable patients is represented by the number of patients on study at the start of each treatment phase. Abbreviations: BASE, baseline; CONS, consolidation; HDM, high-dose therapy with melphalan; IND, induction; $\mathrm{MOB}$, mobilization.

Table 2. Impact of achieved FLCr normalization until the start of maintenance at the latest on PFS and OS. The results of the time-dependent multivariate Cox regression analysis.

\begin{tabular}{ccccc}
\hline \multirow{2}{*}{ Variable } & \multicolumn{2}{c}{ PFS } & \multicolumn{2}{c}{ OS } \\
\cline { 2 - 5 } & HR (95\% CI) & $p$-Value & HR (95\% CI) & $p$-Value \\
\hline Age (per year) & $1.00(0.98-1.01)$ & 0.89 & $1.02(1.00-1.04)$ & 0.06 \\
ISS (II vs. I) & $1.46(1.13-1.90)$ & $<0.01$ & $1.77(1.16-2.71)$ & 0.01 \\
ISS (III vs. I) & $1.82(1.37-2.43)$ & $<0.01$ & $2.91(1.90-4.45)$ & $<0.01$ \\
Adverse cytogenetics (yes vs. no) & $2.12(1.68-2.68)$ & $<0.01$ & $2.96(2.07-4.23)$ & $<0.01$ \\
Treatment arm (B vs. A) & $1.04(0.82-1.31)$ & 0.75 & $1.56(1.12-2.17)$ & 0.01 \\
Response after CONS & $1.04(0.76-1.40)$ & 0.82 & $0.71(0.44-1.15)$ & 0.16 \\
(CR vs. non-CR) & $0.61(0.47-0.79)$ & $<0.01$ & $0.67(0.48-0.93)$ & 0.02
\end{tabular}

Abbreviations: CR, complete remission; HR, hazard ratio; OS, overall survival; PFS, progression-free survival $95 \% \mathrm{CI}, 95 \%$ confidence interval.

Next, we assessed the impact of a FLCr normalization at the predefined time points "after induction" and "after consolidation" on PFS and OS. Achieving a FLCr normalization after induction showed no influence on PFS ( $p=0.11, \mathrm{HR}=0.81,95 \% \mathrm{CI}=0.62-1.05)$ and OS $(p=0.16, \mathrm{HR}=0.75,95 \% \mathrm{CI}=0.50-1.12)$ in multivariable analyses (Table S1). Similar results were seen at the time point after consolidation (PFS: $p=0.12$, HR $=0.82,95 \% \mathrm{CI}=0.64-1.05$, OS: $p=0.34, \mathrm{HR}=0.85,95 \% \mathrm{CI}=0.60-1.19)($ Table S2). 
A

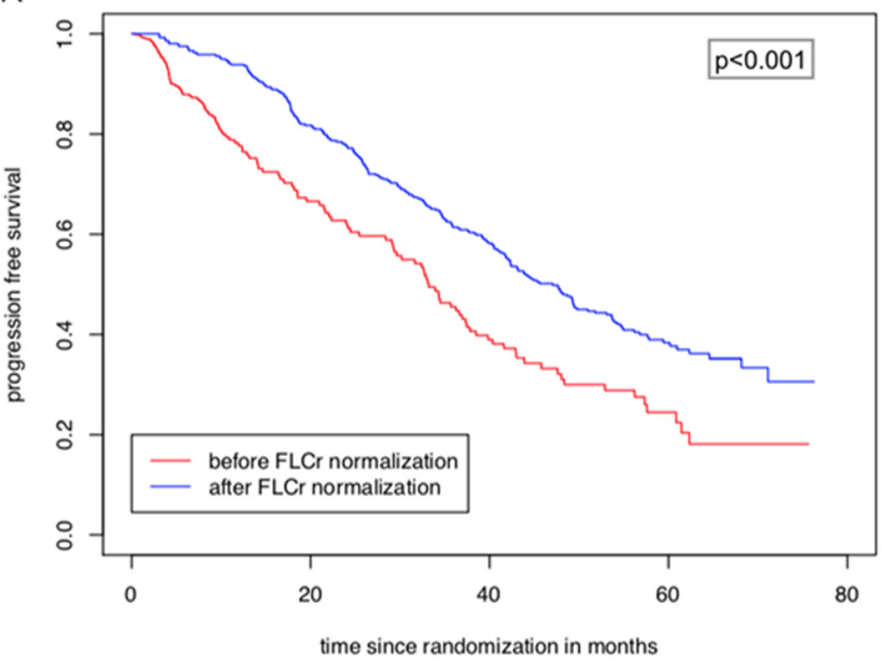

C

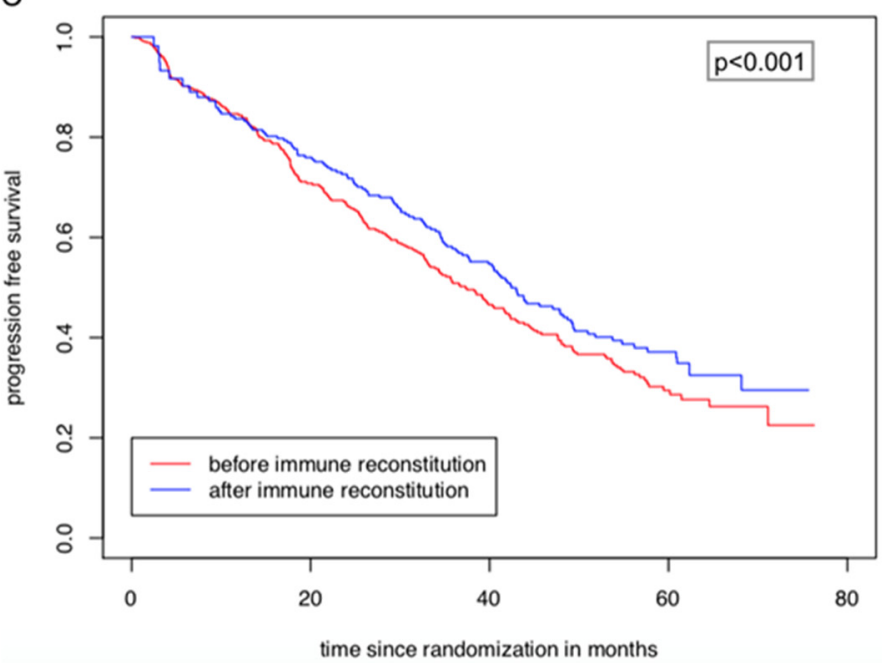

B

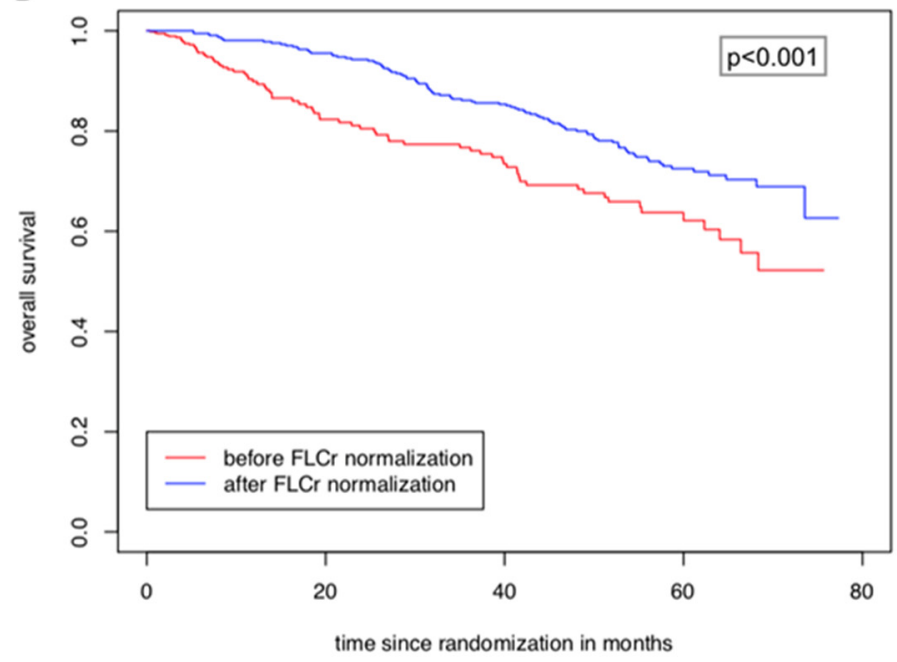

D

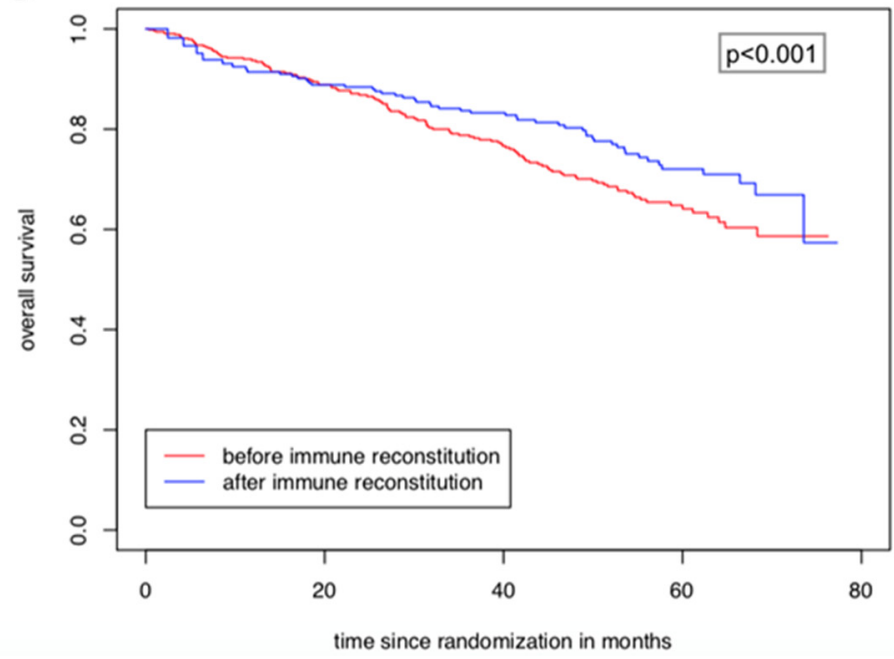

Figure 3. Simon-Makuch Plots showing the risk of progression $(\mathbf{A}, \mathbf{C})$ and death $(\mathbf{B}, \mathbf{D})$ depending on the achievement of FLCr normalization and immune reconstitution. The survival times until a potential achievement of FLCr normalization/immune reconstitution and after a potential achievement are separately shown in two curves. Therefore, one patient can be found in two curves. For example, patients with immunoparesis who achieve immune reconstitution during therapy start in the curve "before immune reconstitution" and switch after the achievement of immune reconstitution in the curve "after immune reconstitution".

\subsection{Achievement of Immune Reconstitution during Therapy in the MM5 Trial and Its Impact on} PFS and OS

At baseline, 9.0\% (53/590) of the patients had normal immunoglobulins, and the amount further decreased to $2.0 \%(11 / 564)$ after induction due to therapy. Immune reconstitution was noted in $15.4 \%(79 / 513)$ of patients after ASCT and in $32.2 \%(147 / 456)$ after consolidation therapy (Figure 4 ).

In total, 227 of 590 patients evaluable for multivariable analyses achieved an immune reconstitution at any time point before the start of maintenance. The achievement of immune reconstitution until the start of maintenance at the latest significantly prolonged PFS $(p=0.04, \mathrm{HR}=0.77,95 \% \mathrm{CI}=0.60-0.99)$ and $\mathrm{OS}(p=0.01, \mathrm{HR}=0.59,95 \% \mathrm{CI}=0.41-0.86)$ in the multivariable time-dependent Cox regression analyses (Table 3). Figure 3C,D show the Simon-Makuch estimators regarding the risk of progression and death depending on immune reconstitution until maintenance. 


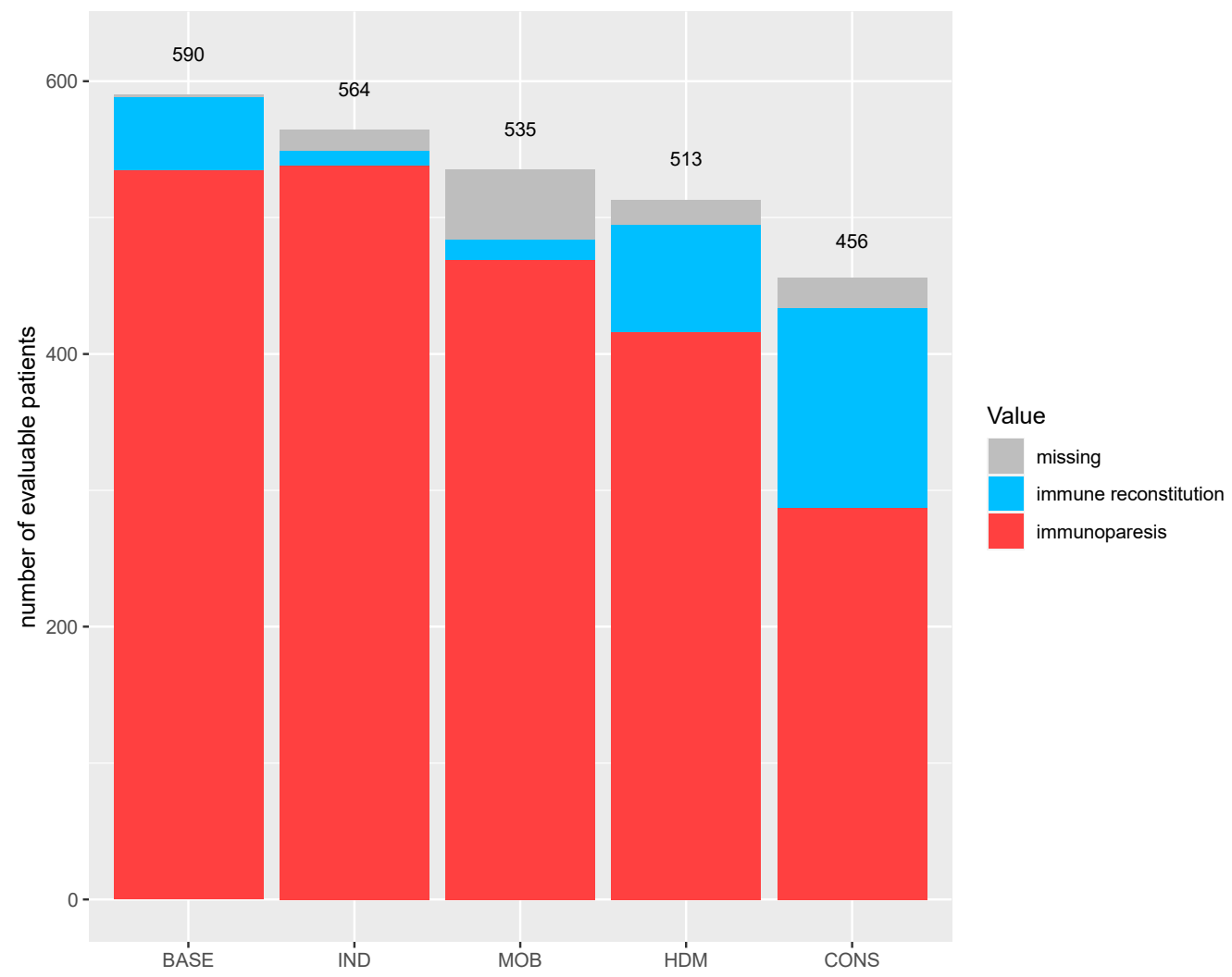

Figure 4. Immune reconstitution during first-line therapy in the MM5 trial. The number of evaluable patients is represented by the number of patients on study at the start of each treatment phase.

Table 3. The impact of achieved immune reconstitution until the start of maintenance at the latest on PFS and OS. The results of the time-dependent multivariate Cox regression analysis.

\begin{tabular}{ccccc}
\hline \multirow{2}{*}{ Variable } & \multicolumn{2}{c}{ PFS } & \multicolumn{2}{c}{ OS } \\
\cline { 2 - 5 } & HR (95\% CI) & $p$-Value & HR (95\% CI) & $p$-Value \\
\hline Age (per year) & $1.00(0.98-1.01)$ & 0.73 & $1.02(1.00-1.04)$ & 0.05 \\
ISS (II vs. I) & $1.43(1.10-1.85)$ & 0.01 & $1.72(1.13-2.63)$ & 0.01 \\
ISS (III vs. I) & $1.88(1.41-2.50)$ & $<0.01$ & $2.97(1.94-4.53)$ & $<0.01$ \\
Adverse cytogenetics (yes vs. no) & $2.09(1.66-2.63)$ & $<0.01$ & $2.97(2.09-4.24)$ & $<0.01$ \\
Treatment arm (B vs. A) & $1.04(0.83-1.30)$ & 0.75 & $1.55(1.11-2.16)$ & 0.01 \\
Response after CONS & $0.98(0.73-1.30)$ & 0.87 & $0.65(0.41-1.04)$ & 0.07 \\
(CR vs. non-CR) & $0.77(0.60-0.99)$ & 0.04 & $0.59(0.41-0.86)$ & 0.01 \\
\hline Immune reconstitution (yes vs. no) & & &
\end{tabular}

The achievement of immune reconstitution after consolidation was associated with a significantly prolonged OS ( $p<0.01, \mathrm{HR}=0.54,95 \% \mathrm{CI}=0.36-0.83)$ (Table S3). The effect on PFS was not significant ( $p=0.15, \mathrm{HR}=0.83,95 \% \mathrm{CI}=0.64-1.07$ ) (Table S3).

\section{Discussion}

Serial measurements of sFLC during therapy in patients with secretory MM have not been recommended by the IMWG so far [6]. However, these measurements might provide important information in terms of prognosis. The sFLC represent tumor burden and have a shorter half-life (T1/2) than immunoglobulins (T1/2 sFLC 2-6 h, T1/2 IgG $20-25 \mathrm{~d}$ ), allowing an earlier evaluation of the response to therapy [26-28]. Furthermore, due to intraclonal heterogeneity in MM, two to ten percent of the patients develop a sFLC escape at relapse [29-31]. Finally, the measurement of light chain excretion in 24-hour urine samples for a response assessment in MM remains controversial because of its dependence on renal function and correct urine collection in the clinical routine [12]. 
In the present study, we analyzed the prognostic impact of a time-dependent FLCr normalization during the course of therapy in newly diagnosed patients with secretory MM treated within the GMMG MM5 trial. To our knowledge, this is the first study assessing the impact of time-dependent FLCr normalization during therapy in a large cohort of patients with secretory MM.

As expected, our analysis demonstrates that during the course of first-line therapy, there is an increasing percentage of patients achieving FLCr normalization with a maximum after consolidation. Tacchetti et al. showed similar rates of patients achieving a normal FLCr after first-line treatment with a bortezomib-based regime [32]. In contrast, in a Japanese study, only $41 \%$ of the patients reached FLCr normalization after a novel agent-containing treatment. However, this may be explained by the small number of patients receiving ASCT $(<20 \%)$ and that there were only a few available novel agents in the time period 2004-2012 [33].

Furthermore, we show, for the first time, that achieving a time-dependent FLCr normalization at any time point before the start of maintenance has a strong beneficial effect on PFS and OS, independent of age, ISS, cytogenetics, treatment arm and even a deep response after consolidation. In contrast, a FLCr normalization at the defined time points after induction and after consolidation alone has no prognostic significance. A possible explanation for this might be that the prognostic effect of FLCr normalization is time-dependent and cannot be attributed to a defined time point during therapy. In addition, by defining certain time points, the event of reaching FLCr normalization at one time point might be too low to reach statistical significance. In contrast, Lopez-Anglada et al. demonstrated that a normal FLCr after induction or after ASCT is associated with a prolonged PFS and OS [10]. The differences might be explained by the number of patients and different variables in the multivariate models. Based on our analyses, we propose serial measurements of sFLC during MM therapy, at least until the achievement of FLCr normalization but preferably also after FLCr normalization to detect a relapse with sFLC escape.

Other studies assessing time-dependent FLCr normalization in secretory MM are not available in the current literature, but there are studies similarly demonstrating a significant effect of a FLCr normalization after therapy on PFS and OS [10,33,34]. Furthermore, Alhaj Moustafa et al. were able to demonstrate a positive prognostic impact of FLCr normalization independent of the response in patients with secretory MM who do not achieve CR in the first-line treatment [11]. The advantage of our study compared to previously published studies is the time-dependent evaluation of sFLC based on serial sFLC measurements.

Interestingly, Abdallah et al. were able to demonstrate that in MM patients who achieve CR and an absence of clonal bone marrow plasma cells in the multiparametric flow cytometry, a pathologic FLCr due to a suppression of the involved, the uninvolved or both sFLC is accompanied with the same outcome compared to a normal FLCr [35]. In contrast, a pathologic FLCr due to an increase in the involved sFLC is associated with a worse outcome. Unfortunately, in our analysis, the reason for an abnormal FLCr was not investigated. However, due to the fact that a pathologic FLCr not related to an increase in the involved sFLC would be classified as "FLCr normalization", a further strengthening of our results would be expected.

In our analysis, the positive prognostic effect of time-dependent FLCr normalization occurred irrespective of whether the achievement of FLCr normalization was lost in between. This is in contrast to the worse prognostic impact of a loss of CR or minimal residual disease (MRD). However, this might be explained by the often therapy-induced abnormal FLCr. This is supported by the work of Abdallah et al., who demonstrated that in more than half of the patients with an abnormal FLCr, this is caused by a suppression of sFLC [35].

Surprisingly, the response after consolidation (CR vs. non-CR) did not show a significant effect on PFS and OS in our time-dependent multivariable Cox regression model. 
This is in contrast to previous studies demonstrating an association between CR and a superior outcome [36,37]. An explanation for this could be that the achievement of a time-dependent FLCr normalization is a better predictor for survival than a response at a single time point. However, it has to be noticed that the rate of CR after consolidation in the MM5 trial is underestimated because bone marrow punctures were not obligatory. Besides the $28.3 \%$ of the patients reaching CR after consolidation, there was a further $28.5 \%$ reaching near $\mathrm{CR}(\mathrm{nCR})$. An impact of the underestimation of $\mathrm{CR}$ and a low $\mathrm{CR}$ rate after consolidation (126/590) cannot be excluded. Furthermore, it can be assumed that due to missing maintenance therapy in patients with $C R$ after consolidation in arms $B$, the positive prognostic impact of CR was weakened.

A relation between sFLC and the IMWG response can be explained by the disease itself. A progression of the disease goes along with an increase in the monoclonal protein but also the involved sFLC, affecting FLCr. Furthermore, the percentage of patients with a normal FLCr increases with the improving response category [11]. However, independent of the response, the positive prognostic impact of FLCr normalization during MM therapy remains.

Because of the effective novel agent-based therapies, there is a need for more precise techniques to detect a residual disease that could be missed by the determination of conventional remission alone. In this context, the determination of MRD by multiparametric flow cytometry or next-generation sequencing is of increasing importance [9], and the results on MRD within the MM5 trial will be presented separately.

After an effective tumor load reduction and the completion of intensive treatment, the recovery of bone marrow and immune system functions leads to a physiological production of polyclonal sFLC and immunoglobulins by plasma cells. In the current analysis, immune reconstitution occurred later than FLCr normalization. This is likely due to the intensive treatment and the strict need for the normalization of all uninvolved immunoglobulins to fulfil this criterion. Immune reconstitution is therefore achieved by a smaller percentage of patients with a maximum of 32.2\% after consolidation. González-Calle et al. showed similar rates six months after ASCT, further increasing to 52\% one year after ASCT [16]. A possible explanation could be the difference in maintenance strategies: Compared to lenalidomide maintenance therapy for two years (arms A1 and A2) or until the achievement of CR (arms B1 and B2) in the MM5 trial, in the Spanish study, only 57\% of the patients received maintenance therapy, which consisted of $80 \%$ of the cases of Interferon- $\alpha$ [16]. Furthermore, Jimenez-Zepeda et al. were able to demonstrate that patients receiving a lenalidomide-based consolidation therapy have a lower rate of immune reconstitution one year after ASCT [38].

We demonstrate that a time-dependent immune reconstitution before the start of maintenance is significantly associated with prolonged PFS and OS. Furthermore, there is a strong effect of immune reconstitution after consolidation on OS, representing the process of physiological B-cell reconstitution after ASCT. This prognostic effect of immune reconstitution can be mainly explained by the fact that immune reconstitution is a marker of the treatment response. During the course of the disease, progressive disease is much more frequent than non-relapse mortality [39]. The most common cause of death due to progressive disease is an infection caused by immunoparesis [40].

Similarly, González-Calle et al. were able to demonstrate a positive prognostic impact by achieving immune reconstitution. However, this impact was seen in the landmark analysis one year after ASCT and not in the landmark analyses conducted at earlier time points [16]. These results are in line with two other studies and can be explained by completed B-cell reconstitution one year after ASCT [38,41,42]. It has to be noted that, currently, there are only a few retrospective studies on the prognostic effect of immune reconstitution after ASCT and that further studies are needed to clarify the optimal time point of assessment. 


\section{Conclusions}

To conclude, two-thirds of the patients with newly diagnosed secretory MM treated within the MM5 trial achieved normalization of the FLCr after consolidation therapy. A time-dependent FLCr normalization at any time point prior to the start of maintenance therapy significantly prolonged PFS and OS independent of age, ISS, cytogenetics, treatment arm and the response after consolidation. Furthermore, a time-dependent immune reconstitution during therapy predicted superior PFS and OS. These results suggest that FLCr normalization and immune reconstitution during therapy constitute important and simple to assess prognostic factors for patients with MM. Therefore, we recommend the serial assessment of sFLC and immunoglobulins during MM therapy.

Supplementary Materials: The following are available online at https:/ /www.mdpi.com/article/10 .3390 /cancers13194856/s1, Figure S1: Flow chart diagram of the treatment within the MM5 trial [18], Material S1: Clinical trial protocol, Table S1: Results of time-dependent multivariate Cox regression analysis: Impact of achieved FLCr normalization at the fixed time point end of induction therapy on PFS and OS, Table S2: Results of time-dependent multivariate Cox regression analysis: Impact of achieved FLCr normalization at the fixed time point end of consolidation therapy on PFS and OS, Table S3: Results of time-dependent multivariate Cox regression analysis: Impact of achieved immune reconstitution at the fixed time point end of consolidation therapy on PFS and OS.

Author Contributions: Conceptualization, E.-M.K., E.K.M., U.B. and H.G.; methodology, E.-M.K., D.T., E.K.M. and A.B.; software, D.T. and A.B.; formal analysis, D.T. and A.B.; investigation, E.M.K., D.T., E.K.M. and A.B.; resources, H.J.S., J.D., K.C.W., U.B., B.B., M.M., H.-W.L., D.H., A.S., S.L., A.J., A.E., S.F., P.B., M.G., H.B., I.W.B., M.H., C.S. and H.G.; data curation, D.T., U.B. and S.L.; writing — original draft preparation, E.-M.K., D.T., E.K.M. and H.G.; writing—review and editing, H.J.S., J.D., K.C.W., A.B., U.B., M.A., B.B., M.M., H.-W.L., D.H., A.S., S.L., A.J., A.E., S.F., P.B., M.G., H.B., M.S.R., I.W.B., M.H. and C.S.; visualization, E.-M.K. and D.T.; supervision, E.K.M. and H.G.; project administration, U.B.; funding acquisition, H.G. All authors have read and agreed to the published version of the manuscript.

Funding: The GMMG-MM5 trial was supported by Celgene, Chugai, Janssen-Cilag and The Binding Site.

Institutional Review Board Statement: The study was conducted according to the guidelines of the Declaration of Helsinki and approved by the local ethics committees of all participating centers (leading ethics committee University of Heidelberg AFmu-119/2010).

Informed Consent Statement: Informed consent was obtained from all subjects involved in the study.

Data Availability Statement: The data presented in this study are available upon request from the corresponding author. The data are not publicly available due to privacy issues.

Acknowledgments: The GMMG thanks the Koordinierungszentrum für Klinische Studien (KKS) Heidelberg for the support of the trial and data monitoring. The GMMG thanks all participating investigators and centers: Facharztpraxis Hämatologie und Onkologie, Aschaffenburg; Praxisnetzwerk Hämatologie/Internistische Onkologie, Bad Honnef; Facharztpraxis Onkologie, Bad Kreuznach; Caritas Krankenhaus Bad Mergentheim, Medizinische Klinik 2, Bad Mergentheim; MVZ BadenBaden, Medizinisches Versorgungszentrum des Klinikums Mittelbaden, Baden-Baden; Charité Universitätsmedizin Berlin, Campus Benjamin Franklin, III. Medizinische Abteilung, Berlin; Charité Universitätsmedizin Berlin, Charité Campus Mitte, Medizinische Klinik mit Schwerpunkt Onkologie und Hämatologie, Berlin; HELIOS Klinikum Berlin-Buch, Klinik für Hämatologie, Onkologie und Immunologie, Berlin; Medizinisches Versorgungszentrum (MVZ), Onkol. Schwerpunkt am OskarHelene-Heim, Berlin; Facharztpraxis Onkologie, Gastroenterologie, Hämatologie, Palliativmedizin, Berlin; Onkologie Seestrasse, Berlin; Klinikum Bielefeld Mitte, Klinik für Hämatologie, Onkologie und Palliativmedizin, Bielefeld; Facharztpraxis Onkologie, Gastroenterologie, Hämostaseologie, Palliativmedizin, Bochum; Universitätsklinikum Bonn, Med. Klinik und Poliklinik III, Schwerpunkte Onkologie, Hämatologie und Rheumatologie, Bonn; Zaho-Bonn, Zentrum für ambulante Hämatologie und Onkologie, Bonn; Johanniter Krankenhaus Bonn, Internistische Onkologie, Bonn; Onkologie Rheinsieg, Praxisnetzwerk Hämatologie/Internistische Onkologie, Bonn-Beuel; Städt. Klinikum Braunschweig, Medizinische Klinik III, Braunschweig; Onkologische Schwerpunktpraxis, Braunschweig; Onkologische Praxis im Krankenhaus Buchholz, Buchholz; Onkologische Schwer- 
punktpraxis, Celle; Klinikum Chemnitz, Innere Medizin III, Chemnitz; Regiomed Kliniken GmbH, Medizinisches Versorgungszentrum (MVZ) Coburg des Klinikums Coburg, Coburg; Carl-ThiemKlinikum Cottbus, II. Medizinische Klinik, Cottbus; Klinikum Darmstadt, Medizinische Klinik V Hämatologie/Onkologie, Darmstadt; Onkologische Schwerpunktpraxis, Darmstadt; Gemeinschaftspraxis für Hämatologie und Onkologie, Medizinisches Zentrum am St.-Josefs-Hospital, Dortmund; Fachpraxis für Hämatologie und Onkologie, Erfurt; Universitätsklinikum Essen, Klinik für Hämatologie, Essen; Evangelisches Krankenhaus Essen-Werden Zentrum für Innere Medizin, Klinik für Hämatologie, Onkologie und Stammzelltransplantation, Essen; St. Antonius-Hospital, Klinik für Hämatologie und Onkologie, Eschweiler; Universitätsklinikum Frankfurt, Goethe-Universität, Medizinische Klinik II, Hämatologie, Onkologie, Rheumatologie, Infektiologie, Frankfurt am Main; Agaplesion Medizinisches Versorgungszentrum (MVZ) Frankfurt, Frankfurt am Main; Krankenhaus Nordwest, Klinik für Onkologie und Hämatologie, Frankfurt am Main; Interdisziplinäres Facharztzentrum (IFS) Frankfurt, Ambulantes Krebszentrum (AKS), Frankfurt am Main; Vitanus GmbH, Frankfurt am Main; Frankfurter Rotkreuz-Kliniken, Klinik Maingau, Abt. Hämatologie/Onkologie und Palliativmedizin, Frankfurt am Main; PIOH-Praxis für Internistische Onkologie und Hämatologie, Frechen; Onkologische Facharztpraxis, Gerlingen; Facharztpraxis für Hämatologie und Onkologie, Gießen; Kath. Krankenhaus Hagen, St.-Josefs-Hospital, Klinik für Hämatologie und Onkologie, Hagen; Asklepios Klinik Altona, Abteilung Onkologie mit Sektion Hämatologie, Hamburg; Asklepios Klinik St. Georg, Abteilung Hämatologie, Onkologie und Stammzelltransplantation, Hamburg; Hämatologisch-Onkologische Praxis Altona (HOPA), Hamburg; Facharztpraxis für Hämatologie und Onkologie, Hamburg; OncoResearch Lerchenfeld UG, Hamburg; Evangelisches Krankenhaus Hamm gGmbH, Medizinische Klinik, Hämatologie/Onkologie, Hamm; Onkologische Schwerpunktpraxis, Hanau; Klinikum Hanau GmbH, Medizinische Klinik III, Hanau; Klinikum Region Hannover, Klinikum Siloah, Onkologie und Palliativmedizin, Hannover; Onkologisches Ambulanzzentrum OAZ Hannover, Hannover; Universitätsklinikum Heidelberg, Medizinische Klinik V, Heidelberg; Onkologische Schwerpunktpraxis, Heidelberg; Onkologische Schwerpunktpraxis Heilbronn, Heilbronn; SLK Kliniken Heilbronn GmbH, Medizinische Klinik III, Heilbronn; Facharztpraxis für Hämatologie und Tumorerkrankungen, Henningsdorf; Universitätsklinikum des Saarlandes, Innere Medizin I, Homburg/Saar; Klinikum Idar-Oberstein, Medizinische Klinik I, Idar-Oberstein; Westpfalz-Klinikum, INN1, Kaiserslautern; Schwerpunktpraxis für Hämatologie und Onkologie, Kaiserslautern; Gemeinschaftspraxis für Hämatologie, Onkologie und Infektiologie, Karlsruhe; Institut für Versorgungsforschung in der Onkologie (InVo), Koblenz; Universitätsklinikum Köln, Klinik I Innere Medizin, Köln; Onkologie Köln, Gemeinschaftspraxis für Onkologie und Hämatologie, Köln; Praxis Internistischer Onkologie und Hämatologie (PIOH), Köln; Kliniken Köln, Krankenhaus Köln-Holweide, Köln; Facharztpraxis für Hämatologie, Onkologie und Gerinnung, Kronach; Onkologisches Zentrum Lebach, Caritaskrankenhaus Lebach, Lebach; Klinikum der Stadt Ludwigshafen am Rhein, Medizinische Klinik A, Ludwigshafen a. Rh.; Onkologische Schwerpunktpraxis Lüneburg, Lüneburg; Universitätsmedizin der Johannes Gutenberg-Universität Mainz, III. Medizinische Klinik, Mainz; MED Facharztzentrum, Gemeinschaftspraxis für Hämatologie und Onkologie, Mainz; Universitätsmedizin Mannheim, III. Medizinische Klinik, Hämatologie und Internistische Onkologie, Mannheim; Mannheimer Onkologie Praxis, Mannheim; Facharztpraxis für Innere Medizin, Hämatologie und Onkologie, Mannheim; Praxis für Innere Medizin, Hämatologie und internistische Onkologie, Marburg; Mühlenkreiskliniken (AöR) Johannes Wesling Klinikum Minden, Hämatologie/Onkologie, Hämostaseologie und Palliativmedizin, Minden; Kliniken Maria Hilf, Krankenhaus St. Franziskus, Klinik für Hämatologie, Onkologie und Gastroenterologie, Mönchengladbach; Städtisches Klinikum München, Klinikum Harlaching, Klinik für Hämatologie, Onkologie und Palliativmedizin, München; Facharztpraxis für Innere Medizin, Hämatologie und Onkologie, Neunkirchen; medius Kliniken, Klinik Nürtingen, Klinik für Innere Medizin Onkologie, Hämatologie, Nürtingen; Onkologische Facharztpraxis, Oberhausen; Paracelsus Kliniken, Klinik Osnabrück, Innere Medizin/Hämatologie und Onkologie, Osnabrück; medius Kliniken, Klinik Ostfildern-Ruit, Innere Medizin, Gastroenterologie und Tumormedizin, Ostfildern; Medizinisches Versorgungszentrum am Siloah St. Trudbert-Klinikum, Pforzheim; Onkologische Praxis Pinneberg, Pinneberg; Gemeinschaftspraxis Innere Medizin/Onkologie, Pirmasens; Facharztpraxis für Onkologie, Rosenheim; Diakonie-Klinikum Schwäbisch Hall, Klinik für Innere Medizin III, Schwäbisch Hall; Zaho-Zentrum für ambulante Hämatologie und Onkologie, Siegburg; Diakonie Klinikum Jung-Stilling, Innere Medizin, Siegen; Gastroenterologie Onkologie Bodensee, Praxis Singen, Singen; Onkologische Schwerpunktpraxis Speyer, Speyer; Marienhospital Stuttgart, Zentrum für Innere Medizin III, Onkologie, Hämatologie, Palliativmedizin, Stuttgart; Krankenhaus der Barmherzigen Brüder Trier, Innere Medi- 
zin I, Trier; Klinikum Mutterhaus der Borromäerinnen Trier, Innere Medizin I, Trier; Onkologische Schwerpunktpraxis am Brüderkrankenhaus Trier, Praxis für Innere Medizin, Nephrologie, Hämatologie und Onkologie, Trier; Onkologie Rheinsieg, Praxisnetzwerk Hämatologie und Internistische Onkologie, Troisdorf; Universität Tübingen, Medizinische Klinik, Abtl. II/Hämatologie, Onkologie, Immunologie und Rheumatologie, Tübingen; OMM Optimed Mundial GmbH, Viersen; Facharztpraxis für Onkologie, Wendlingen/Esslingen; Ammerland Klinik, Medizinische Klinik, Westerstede; Facharztpraxis für Onkologie, Westerstede; Onkologische Schwerpunktpraxis, Wolfsburg-Helmstedt; Praxis Wolfsburg, Wolfsburg.

Conflicts of Interest: E.-M.K.: travel, accommodations, expenses: AMGEN, BMS, Janssen. D.T.: no COI. H.J.S.: honoraria: Janssen Cilag, Takeda, Amgen, BMS/Celgene, Sanofi, Oncopeptides, Abbvie, GSK, Chugai, Pfizer; travel, accommodations, expenses: Janssen, Takeda, Amgen, BMS/Celgene, Sanofi, GSK. E.K.M.: honoraria: Janssen, Celgene, Takeda, GSK; consulting or advisory role: Janssen, Celgene, Takeda, GSK; research funding: Takeda, Celgene/BMS, GSK; travel, accommodations, expenses: Janssen, Takeda, Celgene/BMS, Onyx, Mundipharma, GSK. J.D.: consulting or advisory role: Celgene; speakers bureau: Celgene; travel, accommodations, expenses: Celgene. K.C.W.: honoraria: AMGEN, BMS, Celgene, Novartis, Janssen, Takeda; consulting or advisory role: AMGEN, BMS, Celgene, Juno, Janssen, Adaptive, Sanofi, Takeda; research funding: AMGEN, Celgene, Sanofi, Janssen. A.B.: no COI. U.B.: travel, accommodations, expenses: Sanofi. M.A.: no COI. B.B.: no COI. M.M.: honoraria: Janssen, BMS, Takeda, Celgene, Amgen; consulting or advisory role: Janssen, BMS, Takeda, Celgene, Amgen; research funding: BMS, Incyte; travel, accommodations, expenses: Janssen, BMS, Takeda, Amgen. H.-W.L.: no COI. D.H.: consulting or advisory role: I. Lamkap Bio AG, Discoveric AG; research funding: Celgene AG, Sanofi, Engmab AG; travel, accommodations, expenses: Celgene. A.S.: consulting or advisory role: I. Lamkap Bio AG, Discoveric AG; research funding: Celgene AG, Sanofi, Engmab AG. S.L.: no COI. A.J.: no COI. A.E.: consulting or advisory role: Amgen; travel, accommodations, expenses: Janssen, Amgen. S.F.: consulting or advisory role: Sanofi, BMS, Amgen. P.B.: consulting or advisory role: BMS, AMGEN, Roche, MSD; research funding: BMS; travel, accommodations, expenses: BMS. M.G.: no COI. H.B.: no COI. M.S.R.: honoraria: Celgene, BMS, Novartis, Janssen, Takeda; consulting or advisory role: Celgene, BMS, Novartis, Janssen, Takeda; research funding: Celgene, Novartis, AMGEN; travel, accommodations, expenses: Janssen, BMS, Takeda. I.W.B.: research funding: Celgene, BMS, Janssen. M.H.: honoraria: Novartis, Amgen, Roche, Takeda; consulting or advisory role: Celgene. C.S.: honoraria: BMS, Janssen, Celgene, Novartis, Amgen, Takeda; consulting or advisory role: BMS, Janssen, Celgene, Novartis, Amgen, Takeda; speakers bureau: Takeda; research funding: Takeda, Novartis; travel, accommodations, expenses: BMS, Janssen, Celgene, Novartis, Amgen, Takeda. H.G.: honoraria: Amgen, BMS, Celgene, Chugai, Janssen, Novartis, Takeda; consulting or advisory role: Amgen, BMS, Celgene, Chugai, Janssen, Novartis, Takeda; speakers bureau: Amgen, BMS, Celgene, Janssen, Novartis, Takeda; research funding: Amgen, BMS, Celgene, Chugai, Janssen, Novartis, Takeda; travel, accommodations, expenses: BMS, Celgene, Janssen, Novartis, Takeda. The funders had no role in the design of the study; in the collection, analyses, or interpretation of data; in the writing of the manuscript, or in the decision to publish the results.

\section{References}

1. Bhole, M.V.; Sadler, R.; Ramasamy, K. Serum-Free Light-Chain Assay: Clinical Utility and Limitations. Ann. Clin. Biochem. Int. J. Biochem. Lab. Med. 2014, 51, 528-542. [CrossRef]

2. Snozek, C.L.H.; Katzmann, J.A.; Kyle, R.A.; Dispenzieri, A.; Larson, D.R.; Therneau, T.M.; Melton, L.J.; Kumar, S.; Greipp, P.R.; Clark, R.J.; et al. Prognostic Value of the Serum Free Light Chain Ratio in Newly Diagnosed Myeloma: Proposed Incorporation into the International Staging System. Leukemia 2008, 22, 1933-1937. [CrossRef]

3. García de Veas Silva, J.L.; Bermudo Guitarte, C.; Menéndez Valladares, P.; Rojas Noboa, J.C.; Kestler, K.; Duro Millán, R. Prognostic Value of Serum Free Light Chains Measurements in Multiple Myeloma Patients. PLoS ONE 2016, 11, e0166841. [CrossRef]

4. $\quad$ van Rhee, F.; Bolejack, V.; Hollmig, K.; Pineda-Roman, M.; Anaissie, E.; Epstein, J.; Shaughnessy, J.D.; Zangari, M.; Tricot, G.; Mohiuddin, A.; et al. High Serum-Free Light Chain Levels and Their Rapid Reduction in Response to Therapy Define an Aggressive Multiple Myeloma Subtype with Poor Prognosis. Blood 2007, 110, 827-832. [CrossRef]

5. Kyrtsonis, M.-C.; Vassilakopoulos, T.P.; Kafasi, N.; Sachanas, S.; Tzenou, T.; Papadogiannis, A.; Galanis, Z.; Kalpadakis, C.; Dimou, M.; Kyriakou, E.; et al. Prognostic Value of Serum Free Light Chain Ratio at Diagnosis in Multiple Myeloma. Br. J. Haematol. 2007, 137, 240-243. [CrossRef]

6. Dispenzieri, A.; Kyle, R.; Merlini, G.; Miguel, J.S.; Ludwig, H.; Hajek, R.; Palumbo, A.; Jagannath, S.; Blade, J.; Lonial, S.; et al . International Myeloma Working Group Guidelines for Serum-Free Light Chain Analysis in Multiple Myeloma and Related Disorders. Leukemia 2008, 23, 215-224. [CrossRef] 
7. Rajkumar, S.V.; Dimopoulos, M.A.; Palumbo, A.; Blade, J.; Merlini, G.; Mateos, M.-V.; Kumar, S.; Hillengass, J.; Kastritis, E.; Richardson, P.; et al. International Myeloma Working Group Updated Criteria for the Diagnosis of Multiple Myeloma. Lancet Oncol. 2014, 15, e538-e548. [CrossRef]

8. Durie, B.G.M.; Harousseau, J.-L.; Miguel, J.S.; Bladé, J.; Barlogie, B.; Anderson, K.; Gertz, M.; Dimopoulos, M.; Westin, J.; Sonneveld, P.; et al. International Uniform Response Criteria for Multiple Myeloma. Leukemia 2006, 20, 1467-1473. [CrossRef]

9. Kumar, S.; Paiva, B.; Anderson, K.C.; Durie, B.; Landgren, O.; Moreau, P.; Munshi, N.; Lonial, S.; Bladé, J.; Mateos, M.-V.; et al. International Myeloma Working Group Consensus Criteria for Response and Minimal Residual Disease Assessment in Multiple Myeloma. Lancet Oncol. 2016, 17, e328-e346. [CrossRef]

10. Lopez-Anglada, L.; Cueto-Felgueroso, C.; Rosiñol, L.; Oriol, A.; Teruel, A.I.; Lopez de la Guia, A.; Bengoechea, E.; Palomera, L.; de Arriba, F.; Hernandez, J.M.; et al. Prognostic Utility of Serum Free Light Chain Ratios and Heavy-Light Chain Ratios in Multiple Myeloma in Three PETHEMA/GEM Phase III Clinical Trials. PLoS ONE 2018, 13, e0203392. [CrossRef]

11. Alhaj Moustafa, M.; Rajkumar, S.V.; Dispenzieri, A.; Gertz, M.A.; Lacy, M.Q.; Buadi, F.K.; Hwa, Y.L.; Dingli, D.; Kapoor, P.; Hayman, S.R.; et al. Utility of Serum Free Light Chain Measurements in Multiple Myeloma Patients Not Achieving Complete Response to Therapy. Leukemia 2015, 29, 2033-2038. [CrossRef] [PubMed]

12. Dejoie, T.; Corre, J.; Caillon, H.; Moreau, P.; Attal, M.; Loiseau, H.A. Responses in Multiple Myeloma Should Be Assigned According to Serum, Not Urine, Free Light Chain Measurements. Leukemia 2019, 33, 313-318. [CrossRef]

13. Heaney, J.L.J.; Campbell, J.P.; Iqbal, G.; Cairns, D.; Richter, A.; Child, J.A.; Gregory, W.; Jackson, G.; Kaiser, M.; Owen, R.; et al. Characterisation of Immunoparesis in Newly Diagnosed Myeloma and Its Impact on Progression-Free and Overall Survival in Both Old and Recent Myeloma Trials. Leukemia 2018, 32, 1727-1738. [CrossRef]

14. Chakraborty, R.; Rybicki, L.; Nakashima, M.O.; Dean, R.M.; Faiman, B.M.; Samaras, C.J.; Rosko, N.; Dysert, H.; Valent, J.; Anwer, F. Characterisation and Prognostic Impact of Immunoparesis in Relapsed Multiple Myeloma. Br. J. Haematol. 2020, 189, 1074-1082. [CrossRef] [PubMed]

15. Geng, C.; Yang, G.; Wang, H.; Wu, Y.; Leng, Y.; Zhou, H.; Zhang, Z.; Jian, Y.; Chen, W. Deep and Partial Immunoparesis Is a Poor Prognostic Factor for Newly Diagnosed Multiple Myeloma Patients. Leuk. Lymphoma 2021, 62, 883-890. [CrossRef]

16. González-Calle, V.; Cerdá, S.; Labrador, J.; Sobejano, E.; González-Mena, B.; Aguilera, C.; Ocio, E.M.; Vidriales, M.B.; Puig, N.; Gutiérrez, N.C.; et al. Recovery of Polyclonal Immunoglobulins One Year after Autologous Stem Cell Transplantation as a Long-Term Predictor Marker of Progression and Survival in Multiple Myeloma. Haematologica 2017, 102, 922-931. [CrossRef]

17. Goldschmidt, H.; Mai, E.K.; Dürig, J.; Scheid, C.; Weisel, K.C.; Kunz, C.; Bertsch, U.; Hielscher, T.; Merz, M.; Munder, M.; et al. Response-Adapted Lenalidomide Maintenance in Newly Diagnosed Myeloma: Results from the Phase III GMMG-MM5 Trial. Leukemia 2020, 34, 1853-1865. [CrossRef]

18. Mai, E.K.; Bertsch, U.; Dürig, J.; Kunz, C.; Haenel, M.; Blau, I.W.; Munder, M.; Jauch, A.; Schurich, B.; Hielscher, T.; et al. Phase III Trial of Bortezomib, Cyclophosphamide and Dexamethasone (VCD) versus Bortezomib, Doxorubicin and Dexamethasone (PAd) in Newly Diagnosed Myeloma. Leukemia 2015, 29, 1721-1729. [CrossRef]

19. Bradwell, A.R.; Carr-Smith, H.D.; Mead, G.P.; Tang, L.X.; Showell, P.J.; Drayson, M.T.; Drew, R. Highly Sensitive, Automated Immunoassay for Immunoglobulin Free Light Chains in Serum and Urine. Clin. Chem. 2001, 47, 673-680. [CrossRef]

20. Katzmann, J.A.; Clark, R.J.; Abraham, R.S.; Bryant, S.; Lymp, J.F.; Bradwell, A.R.; Kyle, R.A. Serum Reference Intervals and Diagnostic Ranges for Free Kappa and Free Lambda Immunoglobulin Light Chains: Relative Sensitivity for Detection of Monoclonal Light Chains. Clin. Chem. 2002, 48, 1437-1444. [CrossRef] [PubMed]

21. Hutchison, C.A.; Harding, S.; Hewins, P.; Mead, G.P.; Townsend, J.; Bradwell, A.R.; Cockwell, P. Quantitative Assessment of Serum and Urinary Polyclonal Free Light Chains in Patients with Chronic Kidney Disease. Clin. J. Am. Soc. Nephrol. CJASN 2008, 3, 1684-1690. [CrossRef]

22. Kastritis, E.; Zagouri, F.; Symeonidis, A.; Roussou, M.; Sioni, A.; Pouli, A.; Delimpasi, S.; Katodritou, E.; Michalis, E.; Michael, M.; et al. Preserved Levels of Uninvolved Immunoglobulins Are Independently Associated with Favorable Outcome in Patients with Symptomatic Multiple Myeloma. Leukemia 2014, 28, 2075-2079. [CrossRef]

23. Simon, R.; Makuch, R.W. A Non-Parametric Graphical Representation of the Relationship between Survival and the Occurrence of an Event: Application to Responder versus Non-Responder Bias. Stat. Med. 1984, 3, 35-44. [CrossRef]

24. Kaplan, E.L.; Meier, P. Nonparametric Estimation from Incomplete Observations. J. Am. Stat. Assoc. 1958, 53, 457-481. [CrossRef]

25. Merz, M.; Salwender, H.; Haenel, M.; Mai, E.K.; Bertsch, U.; Kunz, C.; Hielscher, T.; Blau, I.W.; Scheid, C.; Hose, D.; et al. Subcutaneous versus Intravenous Bortezomib in Two Different Induction Therapies for Newly Diagnosed Multiple Myeloma: An Interim Analysis from the Prospective GMMG-MM5 Trial. Haematologica 2015, 100, 964-969. [CrossRef]

26. Gran, C.; Afram, G.; Liwing, J.; Verhoek, A.; Nahi, H. Involved Free Light Chain: An Early Independent Predictor of Response and Progression in Multiple Myeloma. Leuk. Lymphoma 2021, 1-8. [CrossRef]

27. Hansen, C.T.; Pedersen, P.T.; Nielsen, L.C.; Abildgaard, N. Evaluation of the Serum Free Light Chain (SFLC) Analysis in Prediction of Response in Symptomatic Multiple Myeloma Patients: Rapid Profound Reduction in Involved FLC Predicts Achievement of VGPR. Eur. J. Haematol. 2014, 93, 407-413. [CrossRef]

28. Mead, G.P.; Carr-Smith, H.D.; Drayson, M.T.; Morgan, G.J.; Child, J.A.; Bradwell, A.R. Serum Free Light Chains for Monitoring Multiple Myeloma. Br. J. Haematol. 2004, 126, 348-354. [CrossRef] [PubMed] 
29. Brioli, A.; Giles, H.; Pawlyn, C.; Campbell, J.P.; Kaiser, M.F.; Melchor, L.; Jackson, G.H.; Gregory, W.M.; Owen, R.G.; Child, J.A.; et al. Serum Free Immunoglobulin Light Chain Evaluation as a Marker of Impact from Intraclonal Heterogeneity on Myeloma Outcome. Blood 2014, 123, 3414-3419. [CrossRef] [PubMed]

30. Kühnemund, A.; Liebisch, P.; Bauchmüller, K.; zur Hausen, A.; Veelken, H.; Wäsch, R.; Engelhardt, M. 'Light-Chain EscapeMultiple Myeloma'-an Escape Phenomenon from Plateau Phase: Report of the Largest Patient Series Using LC-Monitoring. J. Cancer Res. Clin. Oncol. 2009, 135, 477-484. [CrossRef] [PubMed]

31. Patel, U.H.; Drabick, J.J.; Malysz, J.; Talamo, G. Nonsecretory and Light Chain Escape in Patients with Multiple Myeloma. Clin. Lymphoma Myeloma Leuk. 2018, 18, e515-e519. [CrossRef]

32. Tacchetti, P.; Pezzi, A.; Zamagni, E.; Pantani, L.; Rocchi, S.; Zannetti, B.A.; Mancuso, K.; Rizzello, I.; Cavo, M. Role of Serum Free Light Chain Assay in the Detection of Early Relapse and Prediction of Prognosis after Relapse in Multiple Myeloma Patients Treated Upfront with Novel Agents. Haematologica 2017, 102, e104-e107. [CrossRef] [PubMed]

33. Iwama, K.; Chihara, D.; Tsuda, K.; Ugai, T.; Sugihara, H.; Nishida, Y.; Yamakura, M.; Takeuchi, M.; Matsue, K. Normalization of Free Light Chain Kappa/Lambda Ratio Is a Robust Prognostic Indicator of Favorable Outcome in Patients with Multiple Myeloma. Eur. J. Haematol. 2013, 90, 134-141. [CrossRef]

34. Tacchetti, P.; Cavo, M.; Rocchi, S.; Pezzi, A.; Pantani, L.; Brioli, A.; Testoni, N.; Terragna, C.; Zannetti, B.A.; Mancuso, K.; et al. Prognostic Impact of Serial Measurements of Serum-Free Light Chain Assay throughout the Course of Newly Diagnosed Multiple Myeloma Treated with Bortezomib-Based Regimens. Leuk. Lymphoma 2016, 57, 2058-2064. [CrossRef]

35. Abdallah, N.; Kapoor, P.; Murray, D.L.; Buadi, F.K.; Dingli, D.; Dispenzieri, A.; Gertz, M.A.; Go, R.S.; Gonsalves, W.I.; Hayman, S.R.; et al. Utility of Serum Free Light Chain Ratio in Response Definition in Patients with Multiple Myeloma. Blood Adv. 2020, 4, 322-326. [CrossRef]

36. Lehners, N.; Becker, N.; Benner, A.; Pritsch, M.; Löpprich, M.; Mai, E.K.; Hillengass, J.; Goldschmidt, H.; Raab, M.-S. Analysis of Long-Term Survival in Multiple Myeloma after First-Line Autologous Stem Cell Transplantation: Impact of Clinical Risk Factors and Sustained Response. Cancer Med. 2018, 7, 307-316. [CrossRef]

37. van de Velde, H.J.K.; Liu, X.; Chen, G.; Cakana, A.; Deraedt, W.; Bayssas, M. Complete Response Correlates with Long-Term Survival and Progression-Free Survival in High-Dose Therapy in Multiple Myeloma. Haematologica 2007, 92, 1399-1406. [CrossRef]

38. Jimenez-Zepeda, V.H.; Duggan, P.; Neri, P.; Chaudhry, A.; Tay, J.; Bahlis, N. Immunoparesis and Polyclonal Immunoglobulin Recovery after Auto-SCT for Patients with Multiple Myeloma Treated at a Single Institution. Leuk. Lymphoma 2018, 59, 1920-1926. [CrossRef]

39. Mai, E.K.; Miah, K.; Bertsch, U.; Dürig, J.; Scheid, C.; Weisel, K.C.; Kunz, C.; Munder, M.; Lindemann, H.-W.; Merz, M.; et al. Bortezomib-Based Induction, High-Dose Melphalan and Lenalidomide Maintenance in Myeloma up to 70 Years of Age. Leukemia 2021, 35, 809-822. [CrossRef]

40. Mai, E.K.; Haas, E.-M.; Lücke, S.; Löpprich, M.; Kunz, C.; Pritsch, M.; Knaup-Gregori, P.; Raab, M.S.; Schlenzka, J.; Bertsch, U.; et al. A Systematic Classification of Death Causes in Multiple Myeloma. Blood Cancer J. 2018, 8, 30. [CrossRef]

41. Rueff, J.; Medinger, M.; Heim, D.; Passweg, J.; Stern, M. Lymphocyte Subset Recovery and Outcome after Autologous Hematopoietic Stem Cell Transplantation for Plasma Cell Myeloma. Biol. Blood Marrow Transplant. 2014, 20, 896-899. [CrossRef] [PubMed]

42. Ozaki, S.; Harada, T.; Yagi, H.; Sekimoto, E.; Shibata, H.; Shigekiyo, T.; Fujii, S.; Nakamura, S.; Miki, H.; Kagawa, K.; et al. Polyclonal Immunoglobulin Recovery after Autologous Stem Cell Transplantation Is an Independent Prognostic Factor for Survival Outcome in Patients with Multiple Myeloma. Cancers 2019, 12, 12. [CrossRef] [PubMed] 